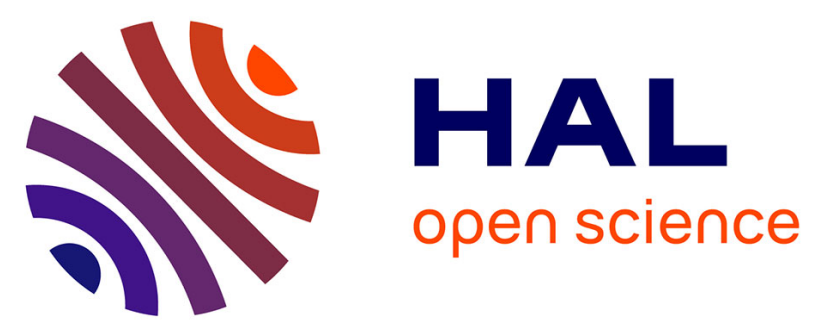

\title{
Application of turbulent pulsating flows to the bacterial removal during a cleaning in place procedure. Part 1: Experimental analysis of wall shear stress in a cylindrical pipe
}

\author{
Walid Blel, Caroline Le Gentil-Lelièvre, Thierry Bénézech, Jack Legrand, \\ Patrick Legentilhomme
}

\section{To cite this version:}

Walid Blel, Caroline Le Gentil-Lelièvre, Thierry Bénézech, Jack Legrand, Patrick Legentilhomme. Application of turbulent pulsating flows to the bacterial removal during a cleaning in place procedure. Part 1: Experimental analysis of wall shear stress in a cylindrical pipe. Journal of Food Engineering, 2009, 90 (4), pp.422-432. 10.1016/j.jfoodeng.2008.07.008 . hal-00400254

\section{HAL Id: hal-00400254 https://hal.science/hal-00400254}

Submitted on 30 Sep 2019

HAL is a multi-disciplinary open access archive for the deposit and dissemination of scientific research documents, whether they are published or not. The documents may come from teaching and research institutions in France or abroad, or from public or private research centers.
L'archive ouverte pluridisciplinaire HAL, est destinée au dépôt et à la diffusion de documents scientifiques de niveau recherche, publiés ou non, émanant des établissements d'enseignement et de recherche français ou étrangers, des laboratoires publics ou privés. 


\title{
Application of turbulent pulsating flows to the bacterial removal during a cleaning in place procedure. Part 1: Experimental analysis of wall shear stress in a cylindrical pipe
}

\author{
W. Blel ${ }^{a}$, C. Le Gentil-Lelièvre ${ }^{b}$, T. Bénézech ${ }^{b}$, J. Legrand ${ }^{a}$, P. Legentilhomme ${ }^{a, *}$ \\ a Université de Nantes, CNRS, GEPEA, UMR 6144, CRTT, 37 Boulevard de l'Université, BP 406, F-44602 Saint-Nazaire Cedex, France \\ b INRA, UR638, 369 Rue Jules Guesde, BP 20039, F-59651 Villeneuve d'Ascq Cedex, France
}

\begin{abstract}
The effects of pulsating turbulent flows on wall shear stress components were investigated in a straight pipe using the non-intrusive electrochemical method. Experiments were made using a new pulsation generator system which allows high amplitude pulsations in addition to a perfect stability of the installation. Maximum pulsation frequency equal to $2.86 \mathrm{~Hz}$ is used, above which fluid inertia dominates over most part of the flow field.

Analysis showed that pulsating flows induce an increase of local velocity gradient at the wall pipe. This result is explained by the periodic renewal of the boundary layers. Spectral analysis showed high increasing rates of the fluctuation energy for the different pulsating conditions in comparison with a steady flow. The tested condition involving a recirculation flow induced a modification in the energy dissipation cascade, which can be explained by the redistribution of eddies size near the wall.
\end{abstract}

\section{Introduction}

In chemical engineering, flow under a steady pressure gradient is generally used in production processes. However, non-steady flows are sometimes applied, and flow fluctuations can be divided into two categories: pulsating flow in which the pressure gradient fluctuates around a non-zero mean value and oscillating flow in which the periodically time-averaged pressure gradient is null. The pulsating flow effects can be beneficial in many applications. Examples are extraction pulsating columns (Grassmann and Tuma, 1978), pulsed combustor for both civil and military uses, reciprocating engines, ramjet and cooling systems for nuclear reactors (Wang and Zhang, 2005).

Several studies with conflicting results were carried out on the effect of the oscillatory motion of the flow on mass and heat transfer (Gomaa and Al Taweel, 2004; Grassmann and Tuma, 1978; Mackley and Stonestreet, 1995). Indeed, Brunold et al. (1989) and Howes et al. (1991) showed that pulsating flows can promote chaotic mixing in a tube, in which radial velocity components are significant. Gbadebo et al. (1999) found that heat transfer was enhanced at medium frequencies of pulsation and reduced at both higher and lower frequencies within their experimental ranges.

\footnotetext{
* Corresponding author. Tel.: +332401726 68; fax: +332 40172618 . E-mail address: patrick.legentilhomme@univ-nantes.fr (P. Legentilhomme).
}

Pérez-Herranz et al. (1999) analysed mass and momentum transfer in an annular electrodialysis cell involving laminar oscillating flow, they found that pulsating flow allows to enhance mass transfer due to the increase of the local velocity gradient at the surface. These authors also showed that the increase in turbulence level by flow pulsation plays a relevant role in convective mass and heat transfer between a solid wall and a liquid. In the other hand, Martinelli et al. (1943) experimentally studied heat transfer, and reported that the frequency has no direct effect on the Nusselt number. In addition, Mao and Hanratty $(1985,1986)$ found that imposed oscillations on a turbulent flow have no effect on the time-mean velocity gradient at the wall. However, only small amplitudes of imposed oscillations are used in their experiments.

Thus, the variety of results found in the literature seems to be related to the type of pulsations generator and to the mean flow rate used during experiments. Unfortunately, in many papers, some important parameters were not considered, especially the amplitude of the oscillations (AI-Haddad and AI-Binally, 1989; Gbadebo et al., 1999).

Experimental studies on pulsating turbulent flows were actively conducted and most of the works have been carried out for fully developed flows with small oscillating velocity amplitudes (Wang and Zhang, 2005). Indeed, the use of high pulsation amplitude is not possible due to the competition between the fluid inertia under high Reynolds number and the harmonic variation of the flow velocity. 


\section{Nomenclature}

A dimensionless amplitude

C ultrasound velocity $(\mathrm{m} / \mathrm{s})$

$D$ diffusion coefficient of the reacting species $\left(\mathrm{m}^{2} / \mathrm{s}\right)$

E fluctuation energy $\left(\mathrm{s}^{-2}\right)$

$f \quad$ frequency of the pulsations $(\mathrm{Hz})$

$f_{\mathrm{e}} \quad$ emitted ultrasounds frequency $\left(\mathrm{s}^{-1}\right)$

$f_{\mathrm{D}} \quad$ Doppler frequency $\left(\mathrm{s}^{-1}\right)$

$f_{\max } \quad$ maximum frequency characterizing hydrodynamic fluctuations $\left(\mathrm{s}^{-1}\right)$

$I(t) \quad$ instantaneous limiting current (A)

$l_{\mathrm{e}} \quad$ equivalent probe length $(\mathrm{m})$

$P_{\mathrm{e}} \quad$ Péclet number (dimensionless)

$R e_{\max } \quad$ maximum Reynolds number (dimensionless)

$\operatorname{Re}_{\mathrm{n}} \quad$ average Reynolds number (dimensionless)

$R e_{\mathrm{p}} \quad$ pulsating Reynolds number (dimensionless)

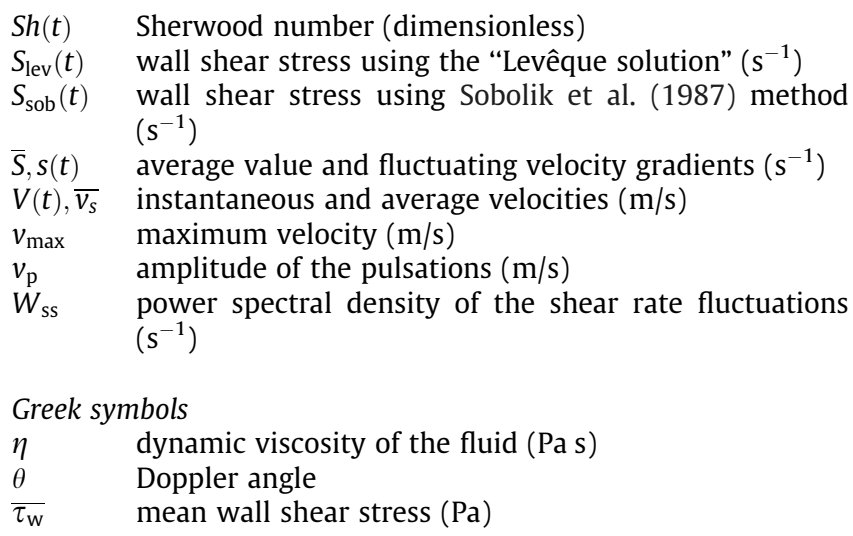

walls. In addition, the system is limited to low pulsation frequencies and there is no net steady flow. For these reasons, the pulsations generator used in this work consists of two ways flow (Fig. 1). The first way, containing the solenoid valve (ASCO/JOUCOMATIC authorized for food applications) allows the generation of the jet fluid flow at high velocity. The second way induces a steady flow component which allows a net flow different from zero at the exit of the pulsations unit when the solenoid valve is closed. Thus, an attenuation of the interruption flow effect (the water hammer phenomenon) generated by the solenoid valve on the equipment can be obtained, ensuring a perfect stability of the whole installation. Pulsations were generated after the adjusting of 3 valves (Fig. 1). The amplitude of pulsations is determined by the difference between the flow rates of automatic valves 1 and 2 . Adjustment procedure consisted in opening the two valves, solenoid and automatic 2 (the flow rate occurs at the 2 ways) and to fix a maximum flow rate with the automatic valve 1 . In the second step, the solenoid valve was closed (the flow rate occurs at the way 2 ) and minimum flow rate was fixed by the automatic valve 2 . The flow rate difference between the two automatic valves 1 and 2 should be sufficient in order to generate pulsations. The frequency of pulsations was adjusted by the sum of the opening and the closing times of the solenoid valve (time cycle).

\subsection{Set-ups}

Measurements of wall shear stresses were carried out in a straight pipe $\left(2.30 \times 10^{-2} \mathrm{~m}\right.$ in inner diameter $)$ made of stainless steel (2B Bright Annealed Finish; average absolute roughness $0.3 \pm 0.05 \mu \mathrm{m})$. Three series of microelectrodes were placed inside the pipe at the upper part, the lower one and the right side (Fig. 1). Each circumferential position contains 18 microelectrodes consisted of cross-sectioned platinum wire $(0.4 \mathrm{~mm})$ embedded in a non-conducting surface. The tested section was placed downstream the pulsations generator after an establishment length of the flow equal to $30 \times D$.

\subsection{Velocity measurements inside pipes}

In this study, conditions of pulsations with different amplitude and frequency were analysed. They were characterized using velocity measurements by Doppler ultrasonic velocimetry (DUV) due to the high sampling and acquisition frequencies of this apparatus in comparison with standard flowmeters. The flow measurement system is composed of the DOP 1000 multigate ultrasonic velocimeter and an ultrasonic transducer (the basic frequency of 


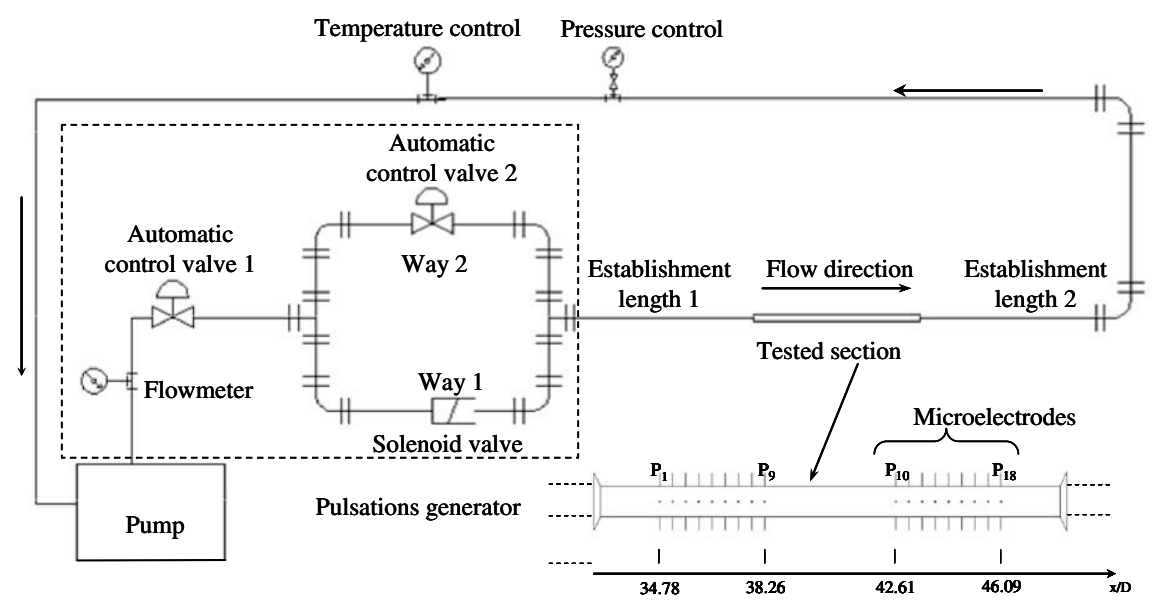

Fig. 1. Schematic diagram of the pulsation generation system and the tested section.

ultrasound is equal to $4 \mathrm{MHz}$ ) both from Signal Processing S.A. (Lausanne, Switzerland). This method needs the use of microparticles suspended in the liquid as tracer with average diameter approximately equal to $80 \mu \mathrm{m}$. Microcapsules of oil having a density close to that of water are used in this study.

The Doppler ultrasonic technique consists in the emission of an ultrasound beam from a transducer, the ultrasound wave being scattered by the moving particles and partial backscattered ultrasound is then received by the same sensor probe.

The particle location is obtained from the time duration between the pulse emission and the echo detection. At the same time, the velocity information, $V$, is derived from the Doppler shift frequency (Takeda, 1995):

$V=\frac{C f_{\mathrm{D}}}{2 f_{e} \cos (\theta)}$

where $C$ is the ultrasound velocity, $f_{\mathrm{D}}$ the Doppler frequency, $f_{e}$ the ultrasound frequency and $\theta$ the Doppler angle.

This method allows to determine instantaneous velocity profiles and then the velocity value at specific positions of the crosssection of the flow (Wang et al., 2003). Pulsations parameters were determined at the center core of the pipe. Velocity measurements were made after an establishment length of the flow equal to $30 \times D$. Thus, the same velocity variation at the center core is observed from this position for each flow condition. At each time, the DUV apparatus allowed registration of one-dimensional velocity profile throughout the cross-section of the flow. Temporal evolution of the velocity at the central position was obtained by the registration of some profiles with fixed repetition duration between successive profiles corresponding to the frequency acquisition. According to the Shannon theorem, the frequency acquisition of the recorded profiles should be higher enough to sample the whole frequencies range of the flow under pulsating conditions. In this study, a frequency repetition of the recorded profiles equal to $54 \mathrm{~Hz}$ was selected.

\subsection{Electrochemical measurements}

The electrochemical technique, described by Reiss and Hanratty (1963), allowed the local mass transfer coefficient at the wall to be measured non-intrusively. This method consists in measuring the limiting diffusional current given by a redox reaction Eq. (2), in a potential range where the current at microelectrodes, flushmounted inside the tested pipe, is only controlled by the diffusion-convection flux of the reacting species towards the wall.
$\mathrm{Fe}(\mathrm{CN})_{6}^{3-}+\mathrm{e}^{-} \rightarrow \mathrm{Fe}(\mathrm{CN})_{6}^{4-}$

The electrolytic solution was a mixture of potassium ferricyanide $\left(3 \times 10^{-3} \mathrm{~mol} / \mathrm{L}\right)$, potassium ferrocyanide $\left(5 \times 10^{-2} \mathrm{~mol} / \mathrm{L}\right)$ and sodium hydroxide $(0.5 \mathrm{~mol} / \mathrm{L})$. The density of this solution is $1028 \mathrm{~kg} / \mathrm{m}^{3}$ and its dynamic viscosity is $0.985 \times 10^{-3} \mathrm{Pas}$ at $22{ }^{\circ} \mathrm{C}$. The diffusion coefficient of ferricyanide ions was measured using a rotating disk electrode, the value obtained at $22{ }^{\circ} \mathrm{C}$ is $3.65 \times 10^{-10} \mathrm{~m}^{2} / \mathrm{s}$.

In practice, it exists different models used for the calculation of the wall shear rate. Reiss and Hanratty (1963) proposed a relation between the instantaneous limiting current, $I(t)$, given in the dimensionless form of the Sherwood number, $\operatorname{Sh}(t)$, and the shear rate at the surface of the electrode, $S_{\mathrm{lev}}$, which is known as the "Lévêque solution":

$S_{\mathrm{lev}}(t)=\frac{D}{l_{\mathrm{e}}^{2}}\left(\frac{\operatorname{Sh}(t)}{0.807}\right)^{3}$

where $l_{\mathrm{e}}$ is the equivalent length of the working electrode and $D$ the diffusion coefficient of the active species.

However, for high frequency fluctuating flows, the Lévêque solution is no longer valid. Labraga et al. (2002) showed that the concentration boundary layer is insensitive to fluctuation. Indeed, an attenuation of the signal fluctuation and a phase shift are observed (Rehimi et al., 2006). Sobolik et al. (1987) have introduced another technique based on the correction of the wall shear rate obtained by the Lévêque solution by adding a term deduced from the transient response of the probe multiplied by the time derivative of the mass transfer rate, $S h(t)$. For high Péclet numbers, $P_{\mathrm{e}}$, Sobolik et al. (1987) method gives similar results as those obtained using the inverse method applied to the diffusion-convection equation and which remains the most rigorous technique to be used to calculate the "true" wall shear rate (Rehimi et al., 2006). The analytic solution of Sobolik et al. (1987) is described by the following equation:

$S_{\mathrm{sob}}(t)=S_{\mathrm{lev}}(t)+1.204 \frac{\partial S h(t)}{\partial t}$

The instantaneous value of the wall shear rate, $S_{\text {sob }}$, is represented as the sum of an average value, $\bar{S}$, and a fluctuating one, $s(t)$ :

$S_{\mathrm{sob}}(t)=\bar{S}+s(t)$ with $\overline{s(t)}=0$

The wall shear rate multiplied by the fluid viscosity, $\eta$, gives the average local wall shear stress, $\overline{\tau_{\mathrm{w}}}$ : 
$\overline{\tau_{\mathrm{w}}}=\eta \bar{S}$

In order to obtain the Power Spectral Density (PSD) of the shear rate fluctuations, $W_{\mathrm{ss}}$, and then quantify the corresponding fluctuation energy, a signal processing method was applied on the fluctuating component of the instantaneous value of the wall shear rate, $S_{\mathrm{sob}}(t)$.. This method allows frequencies representation of the flow energy near the wall and thereafter to give physical signification to the instantaneous signal. The signal processing was made according Quinquis (2000) procedure which consists to divide the initial shear rate signal, $S_{\text {sob }}$, into elementary windows. Each window allowed the calculation of an elementary spectrum, using the multiplication by a Hanning function, to avoid "lobe" effects (Bellanger, 2002) and the application of a discrete Fourier transform. Thus, the shear rate fluctuations PSD was obtained after the averaging of elementary spectra. The increase of elementary spectra number allowed the attenuation of the irreproducible peaks induced by experimental noisy conditions. Then, the integration of the spectrum was implemented in order to calculate the fluctuation energy, $\overline{s^{2}}$, noted $E$ :

$\overline{s^{2}}=E=2 \int_{0}^{f_{\max }} W_{\mathrm{ss}}(f) \mathrm{d} f$

where $f_{\max }$ is the maximum frequency characterizing hydrodynamic fluctuations.

The different steps of the spectral analysis are summarised in Fig. 2.

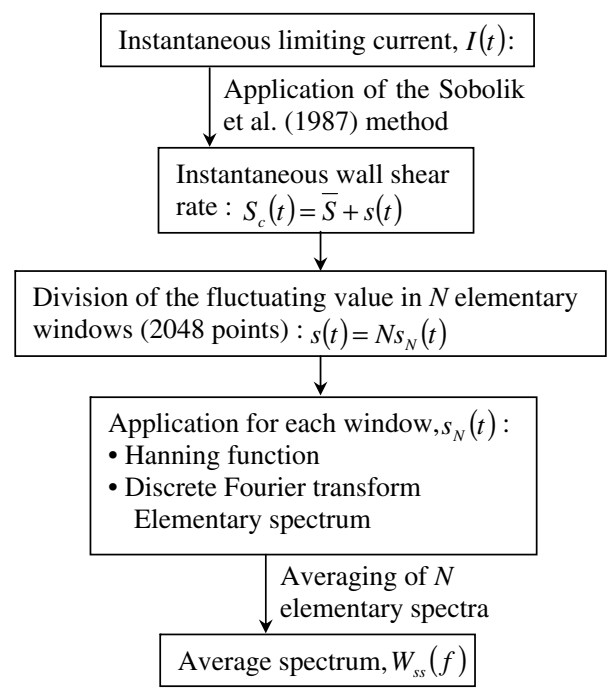

Fig. 2. Main steps in the determination of the shear rate fluctuations PSD.

\section{Results and analysis}

\subsection{Pulsations generator characterization}

Velocity measurements at the center core of the pipe allow pulsation generator characterization for different flow rates and time cycles, respectively regulated with the two automatic valves and the solenoid one. Table 1 gives pulsations parameters corresponding to each condition, with Reynolds numbers $R e_{\max }, R e_{\mathrm{p}}$ and $R e_{\mathrm{n}}$ respectively based on the maximum velocity, $v_{\max }$, the amplitude of the pulsation, $v_{\mathrm{p}}$ and the average velocity, $\bar{v}_{\mathrm{s}}$. Limits of pulsation generator system are then determined for a pulsating turbulent flow, in addition to the perfect stability of the whole installation. Instantaneous variations of the velocity for some pulsations conditions are presented in Fig. 3. Each condition is defined by: opening time - closing time (minimum flow rate - maximum flow rate). The velocity evolution can be represented by a sinusoidal oscillation around a periodically time-averaged value of the mean velocity and can be formulated as follows:

$V(t)=\overline{v_{s}}(1+A \sin (2 \pi f t))$

with the base frequency $f$, the average velocity $\overline{v_{s}}$, the dimensionless amplitude $A\left(A=v_{\mathrm{p}} / \overline{v_{s}}\right)$ and the amplitude of the pulsations, $v_{\mathrm{p}}$.

Fig. 3 shows that the velocity evolution is closely related to both pulsations parameters and exhibits non-harmonic variations according to Eq. (8). Indeed, in some cases (Fig. 3a), half-periods are not symmetric despite analogy between the opening and the closing times of the solenoid valve. However, conditions (e) and (h) exhibit instantaneous evolution close to the theoretical repartition according to Eq. (8). The chosen pulsations parameters allow this velocity evolution $(100 \mathrm{~ms}$ and $300 \mathrm{~ms}$ respectively for the opening and the closing times of the solenoid valve and amplitude pulsation, $v_{\mathrm{p}}$, equal to $0.73 \mathrm{~m} / \mathrm{s}$ ). Velocity analysis allows determining the maximum frequency of pulsations above which no effects of the imposed oscillations on the time-mean velocity are observed. In this case, the fluid inertia dominates over most part of the flow-field. Thus, minimum closing and opening times respectively around $300 \mathrm{~ms}$ and $50 \mathrm{~ms}$ represent limits which allow harmonic variations of the velocity under turbulent flow rate in addition to a perfect stability of the installation. For this reason, maximum frequency of pulsations equal to $2.86 \mathrm{~Hz}$ is used. The dimensionless amplitude, $A$, allows to put forward a special type of pulsating flow with recirculation at the center core of the pipe. This flow presents beneficial effects on mass and heat transfer (Paek et al., 1999; Pérez-Herranz et al., 1999) when the amplitude of the pulsations is higher than the average velocity $(A>1)$. This case is shown in Fig. 3 with the pulsation condition (i). In this case, flow at the center core of the pipe presents negative velocity values, which confirms the existence of a counter-flow recirculation zone.

Table 1

Hydrodynamic parameters for each pulsation condition

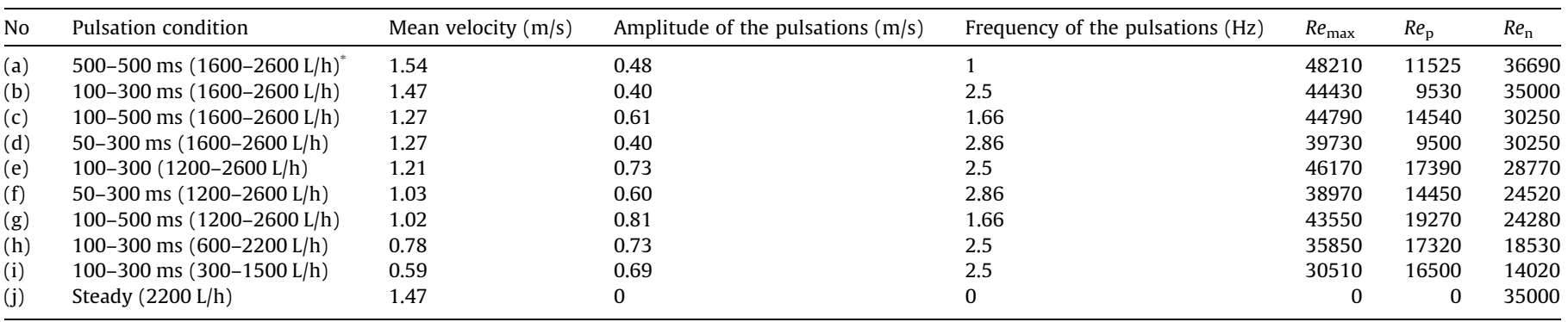

Opening time - Closing time (minimum flow rate - maximum flow rate). 

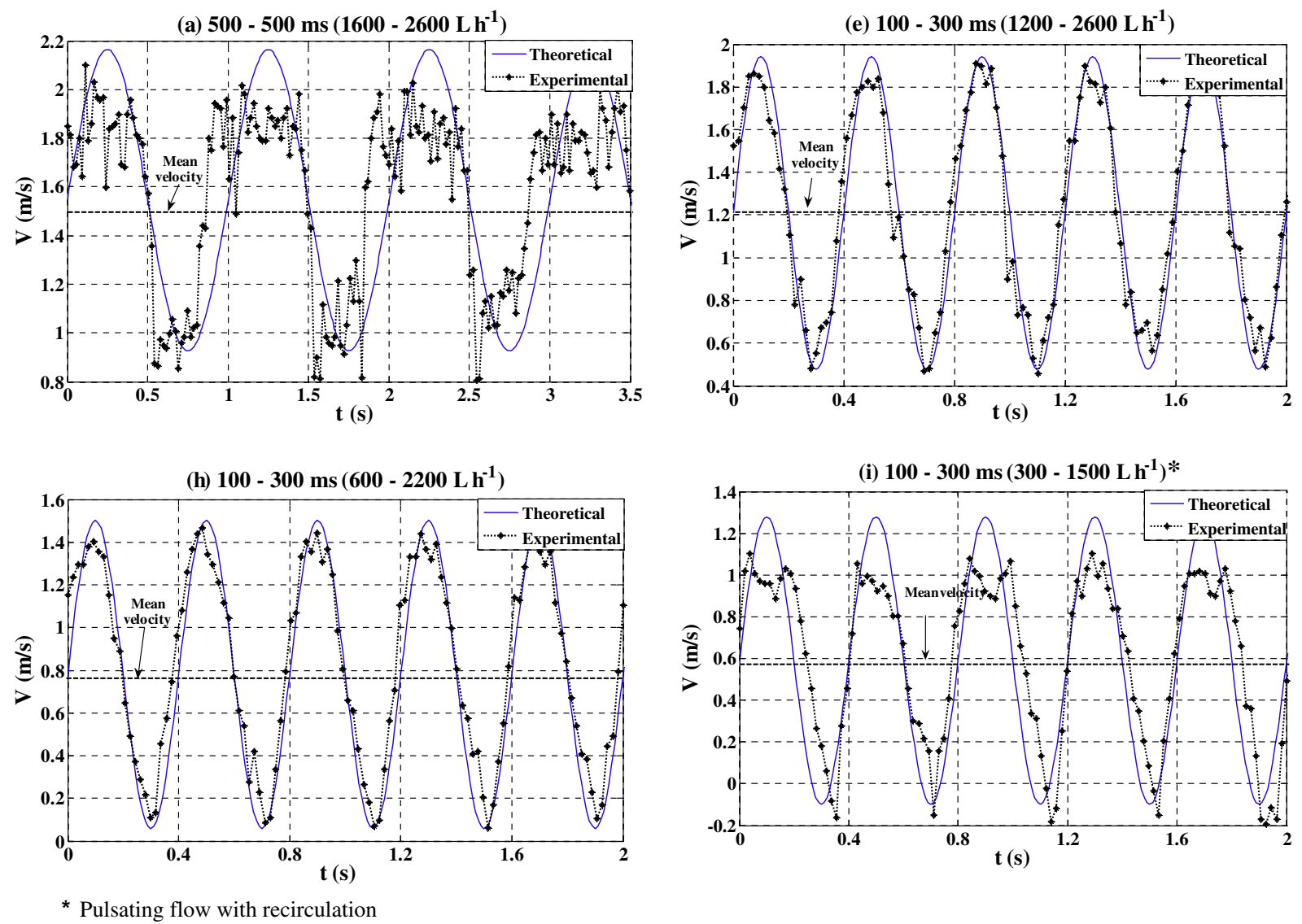

Fig. 3. Examples of instantaneous velocity evolution at the center core of the pipe for different pulsating conditions (respectively (a), (e), (h) and (i) of Table 1).

\subsection{Flow pulsations effects on wall shear stress components}

Electrochemical measurements have been carried out for different flow conditions and comparison have been made between pulsating conditions and steady flow at $2200 \mathrm{~L} / \mathrm{h}$ (mean velocity corresponding to $1.47 \mathrm{~m} / \mathrm{s}$ for $2.30 \times 10^{-2} \mathrm{~m}$ inner pipe diameter). Local wall shear stress measurements are made on 18 microelectrodes sampling three circumferential positions as described in Fig. 1. Due to the high number of data collected at each position, variance analysis were performed separately for mean shear stress and fluctuation energy of shear rate for the different conditions. Three factors are studied: flow conditions (seven pulsed flows conditions and a steady flow at $2200 \mathrm{~L} / \mathrm{h}$ ), circumferential position measurement (upper part, lower one and right side) and axial position of the probe (Fig. 1). Analysis showed a significant difference between the three circumferential positions which reveals the asymmetric behaviour of the flow at the exit of the pulsation system even for the steady flow condition $(P$-values $<0.0001$ and 0.0002 respectively for the mean shear stress and the fluctuation energy). This result can be explained by the non-established flow at the tested section, despite the straight length managed downstream the pulsation system. In addition, a significant difference is observed between various pulsating conditions and the steady flow ( $P$-values $<0.0001$ for the mean shear stress and the fluctuation energy). However, statistical analysis testing the response homogeneity of probes for the different conditions showed a significant uniformity of results for probes at the same circumferential position ( $P$-values $<0.0001$ for the mean shear stress and the fluctuation energy). Thus, according to these results, averaging is made for probes located at the same circumferential position. Thus, the comparison of the different flow conditions is done between those 3 measurement positions.

\subsubsection{Mean wall shear stress}

Fig. 4 shows wall shear stress values obtained at the three tested circumferential positions for the different flow conditions. Comparisons are made with the steady flow $(2200 \mathrm{~L} / \mathrm{h})$. The condition (a) presents mean fluid velocity slightly greater than steady flow one (respectively $1.54 \mathrm{~m} / \mathrm{s}$ against $1.47 \mathrm{~m} / \mathrm{s}$ ) and the weakest pulsation parameters of the tested range $(1 \mathrm{~Hz}$ and $0.48 \mathrm{~m} / \mathrm{s}$ respectively for the frequency and the amplitude). High increasing rates of shear stress in comparison with steady flow are observed at the three circumferential locations for this condition $(300 \%$, $170 \%$ and $130 \%$ respectively on the lower, the right and the upper parts). Instantaneous variations of the Sherwood number (Fig. 5) present harmonic repartition with equal period around $1 \mathrm{~s}$, which corresponds to the time cycle of the solenoid valve. However, despite the equal opening and closing times of the solenoid valve, $\operatorname{Sh}(t)$ evolution is not sinusoidal and presents more maximum values duration per cycle. This result allows to explain the increase of wall shear stress values in comparison with that obtained in steady flow $(2200 \mathrm{~L} / \mathrm{h})$. Two main reasons may justify the $S h(t)$ evolution:

- This variation can be induced by the frequency response of the electrochemical probe on the mass transfer in the concentration boundary layer. This effect can induce the attenuation and phase lag of the wall shear fluctuation. However, previous studies showed that the frequency response effect of the probe is not significant due to the instantaneous behaviour of the electrochemical reaction (Deslouis et al., 1990; Mao, 1995). In 

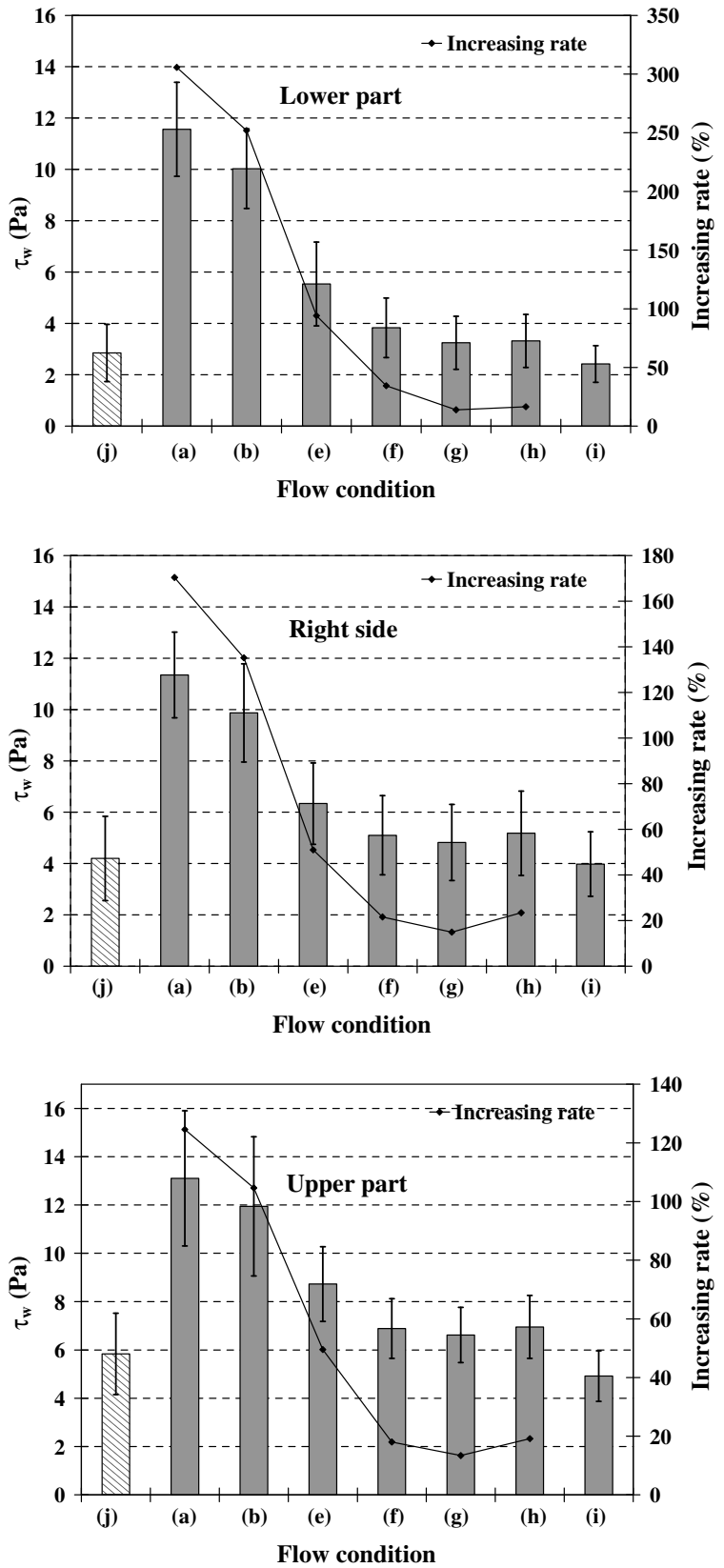

Fig. 4. Comparison of mean wall shear stresses between the tested flow conditions and increasing rates compared to the steady flow. (Increasing rate $=100 \times$ (pulsating value - steady value)/steady value).

addition, the observation of the instantaneous evolution of the wall shear rate, $S_{\mathrm{sob}}$, allows the verification of this observation. Fig. 5 presents a similar instantaneous variation of $S_{\text {sob }}(t)$ and $S h(t)$. Since, $S_{\text {sob }}(t)$ can be considered as similar to the "true" wall shear rates obtained by the inverse method applied to the diffusion-convection equation for high Péclet numbers (Rehimi et al., 2006), the observed variation of the mass transfer rate, $S h(t)$, is not obtained due to the frequency response of the microelectrode, but it would be rather due to the near probe hydrodynamics.

- Pulsations effects on the wall boundary layer structure can explain this $S h(t)$ variation. Indeed, pulsations application on turbulent fluid flow induces, in general, flow relaminarisation at the center core and the modification of the boundary layer thickness near the wall. According to Cousteix (1989), under

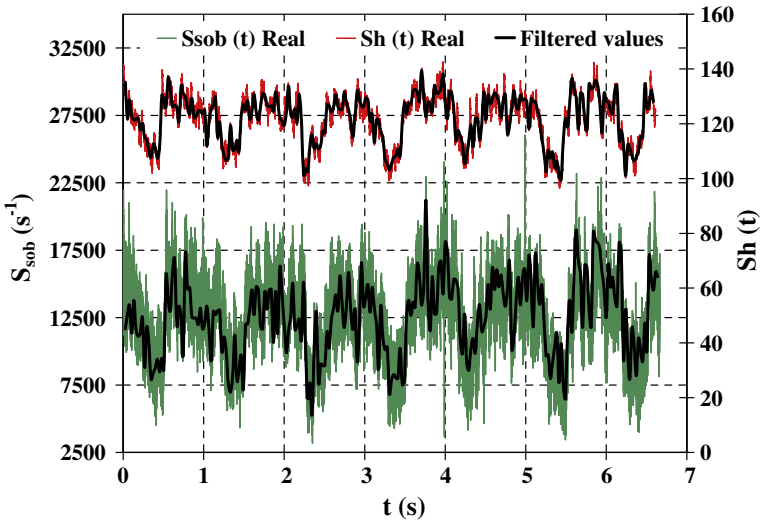

Fig. 5. Instantaneous variations of the Sherwood number, $\operatorname{Sh}(t)$, and the wall shear rate, $S_{\text {sob }}(t)$, measured at the lower part of the pipe on microelectrode $\mathrm{N} 7$.

turbulent flow, the maximum of shear stress is obtained with transitional boundary layer. Thus, the succession of harmonic pulsations induces an increase in the local velocity gradient at the wall maintaining high residence times and preventing the flow establishment and the boundary layer thickening. The increase in the mass transfer coefficient, $\operatorname{Sh}(t)$, can be explained by the renewal of the concentration boundary layer which induces the increase in $S_{\text {sob }}(t)$ values.

For the same average velocity than in steady flow $(1.47 \mathrm{~m} / \mathrm{s})$, the condition (b) presents increasing rates of shear stress varying between $250 \%$ and $105 \%$ for the three circumferential positions. However, wall shear stresses are less important in the condition (e) (increasing rates varying between $95 \%$ and $50 \%$ respectively at the lower and the upper parts). This condition exhibits mean velocity lower than condition (b) and the pulsation amplitude is more important $(0.73 \mathrm{~m} / \mathrm{s})$. Fig. 6 shows an example of the $S h(t)$ evolution for the two conditions (b) and (e) at microelectrode No 3 , localised at the upper part of the tested pipe and reveals similar maximum values per cycle $(S h \approx 130)$. However, the reduction of the mean velocity for condition (e) can explain the decrease of the mean wall shear stress compared with condition (b). In addition, the high pulsation amplitude of condition (e) allows to obtain harmonic and distinguishable cycles of $\operatorname{Sh}(t)$. Conditions (f) and (g) present nearer mean flow velocity and different frequency of pulsations $(1.03 \mathrm{~m} / \mathrm{s}$ and $2.86 \mathrm{~Hz}$ against $1.02 \mathrm{~m} / \mathrm{s}$ and $1.66 \mathrm{~Hz}$ respectively for conditions (f) and (g)). Electrochemical measurements show that wall shear stress values are more important for condition (f) for the three analysed positions (increasing rates varying between $35 \%$ and $18 \%$ for condition (f) against $15 \%$ and $13 \%$ for condition (g)). Despite a more important pulsation amplitude in condition $(\mathrm{g})(0.81 \mathrm{~m} / \mathrm{s}$ against $0.60 \mathrm{~m} / \mathrm{s})$, the pulsations frequency parameter remains more effective in the increase of wall shear stress. Fig. 7 showed that for the same interval time, the condition (f) presents more important number of $S h(t)$ peaks at high value than the condition $(\mathrm{g})$ and can explain the obtained wall shear stress.

Condition (h) presents a sinusoidal velocity variation according to Eq. (8) and mean velocity equal to the half of the steady flow value $(0.78 \mathrm{~m} / \mathrm{s})$. The amplitude of the pulsations is high enough, which allows to get a Reynolds pulsation number close to that calculated according to the mean velocity $\left(R e_{\mathrm{p}}=17,320\right.$ and $R e_{\mathrm{n}}=18,530$ respectively). This parameter can explain the increase of the shear stress in comparison with steady flow, despite the low mean velocity (increasing rates varying between $16 \%$ and $23 \%$ for the three tested positions). 

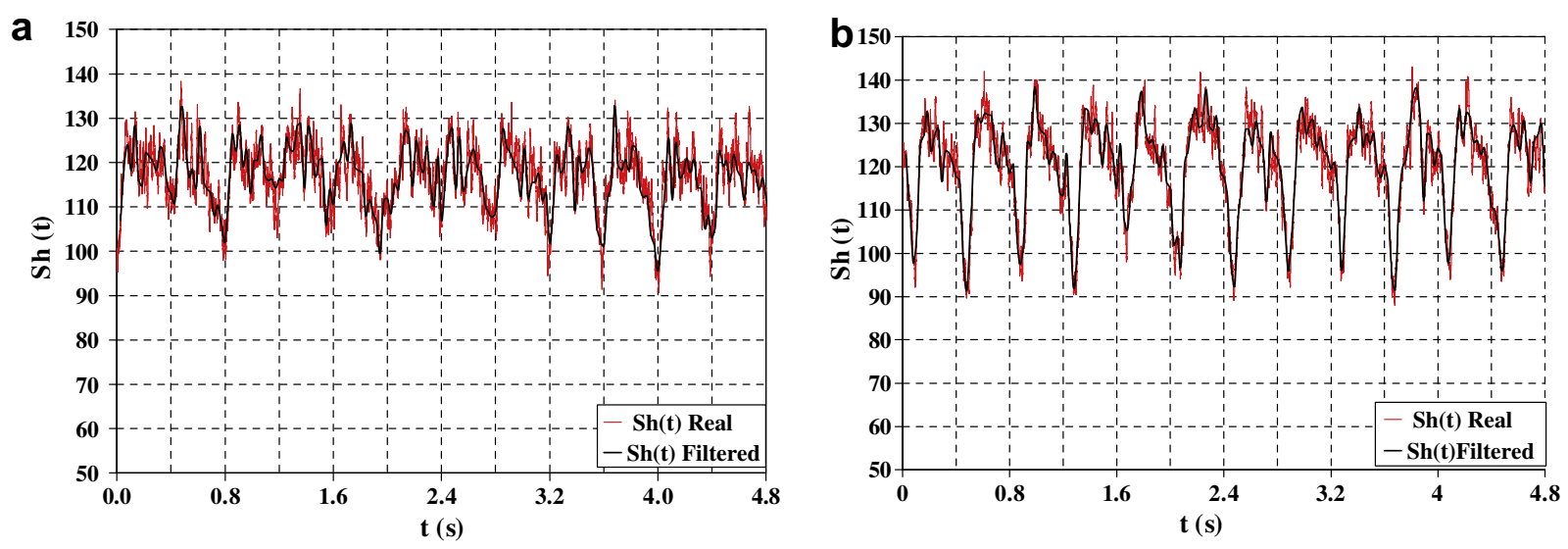

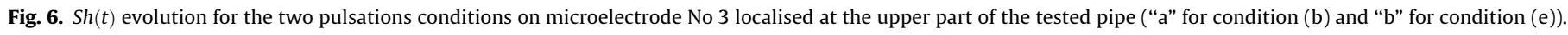
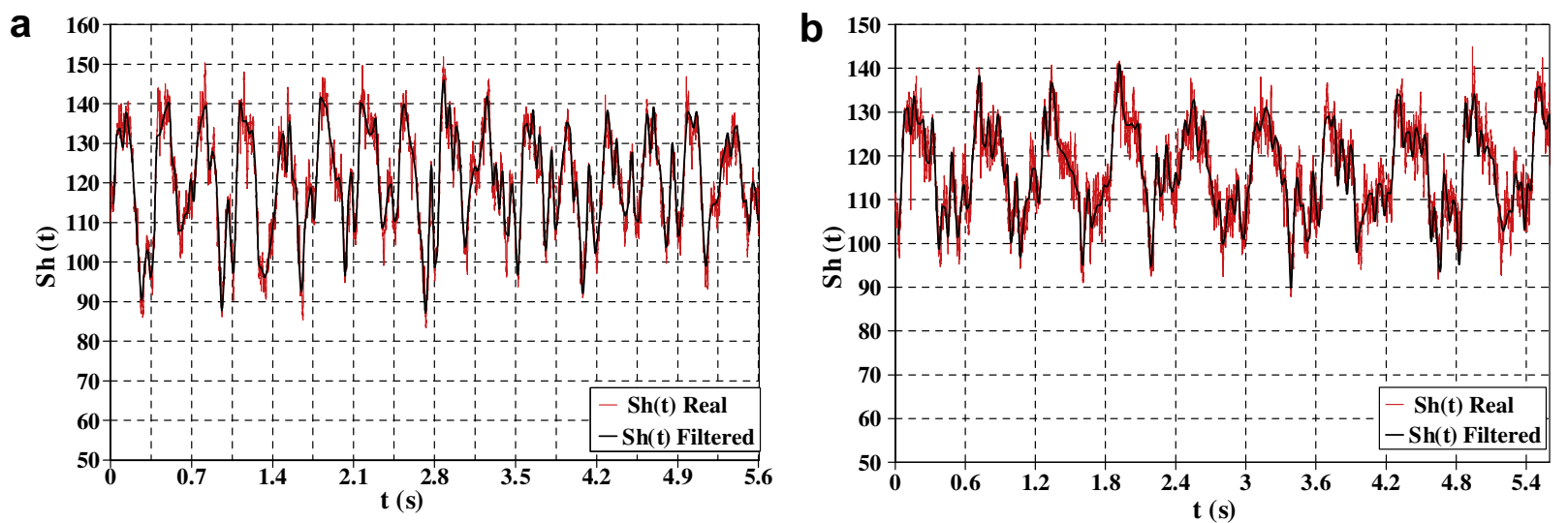

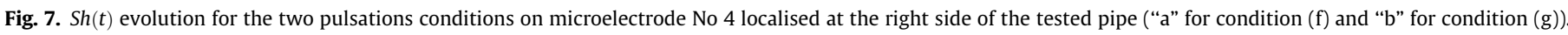

Condition (i) corresponds to a pulsed flow with recirculation at the center core of the pipe. This condition presents amplitude of pulsations greater than the mean velocity. Despite the low Reynolds number induced by this condition in comparison with the steady flow $(R e=14,020$ against $R e=35,000)$, high wall shear stress values are observed under this condition which remains close to the steady flow one. Indeed, the high amplitude of pulsations induces an important modification in the boundary layer structure, which allows the increase in the mass transfer coefficient and explain the obtained result. The beneficial effect of this flow pattern is already proven in many industrial applications like the ultrafiltration in a baffled tubular membrane system (Finnigan and Howell, 1989) and on the cleaning of whey protein soils (Gillham et al., 2000).

To sum up, wall shear stress measurements with different pulsating conditions have shown an increase of mean shear values for a wide range of mean flow velocities lower than that for steady flow condition studied. This result has been explained by the pulsations effects on the wall boundary layer structure. In addition, results have illustrated the role of the mean velocity under pulsed flow in the increase of the shear stress when the amplitude and the frequency of the pulsations are not high enough. On the other hand, for the same mean velocity, the frequency of the pulsations has been proven to be more effective on the shear stress than the amplitude parameter. Finally, the amplitude of the pulsations has a beneficial effect on the shear stress when the mean velocity is not high enough.

\subsubsection{Fluctuation energy of the shear rate}

In turbulent flows, instantaneous fluctuation velocities are induced by individual fluid elements or eddies motion (Brodkey and Hershey, 1988). A statistical analysis allows the characterization of such random phenomena. However, for a pulsating flow, the random fluctuations are masked by the harmonic pulsations imposed at the chosen frequency and amplitude, which allows the fluctuation flow control.

Fig. 8 presents the fluctuation energy, $E$, obtained by the integration of the Power Spectral Density (PSD) of the shear rate fluctuations, $W_{s s}$, for different flow conditions. Increasing rates are calculated according to the steady flow. The variance analysis showed a significant difference between the steady flow and pulsed flow conditions $(P$-value $<0.0001)$. Fluctuation energies difference between the three analysed circumferential positions exhibit the asymmetric behaviour of the flow downstream the pulsation unit. However, for the three cases, fluctuation energy is more important with pulsed flow.

Conditions (a) and (b) present increasing rates of the fluctuation energy higher than $250 \%$ at the lower part and around $170 \%$ at the right side. Spectral densities of the velocity gradient fluctuations at the wall reveal peaks observed at the corresponding pulsations frequency of each condition and at their harmonics (Fig. 9a and b). At low frequencies, these peaks can explain the increase of the fluctuation energy in comparison with the steady flow. In addition, the superposition of pulsations induces a fluctuation energy increase for a range of frequencies as shown in Fig. 9(a). Indeed, the begin- 

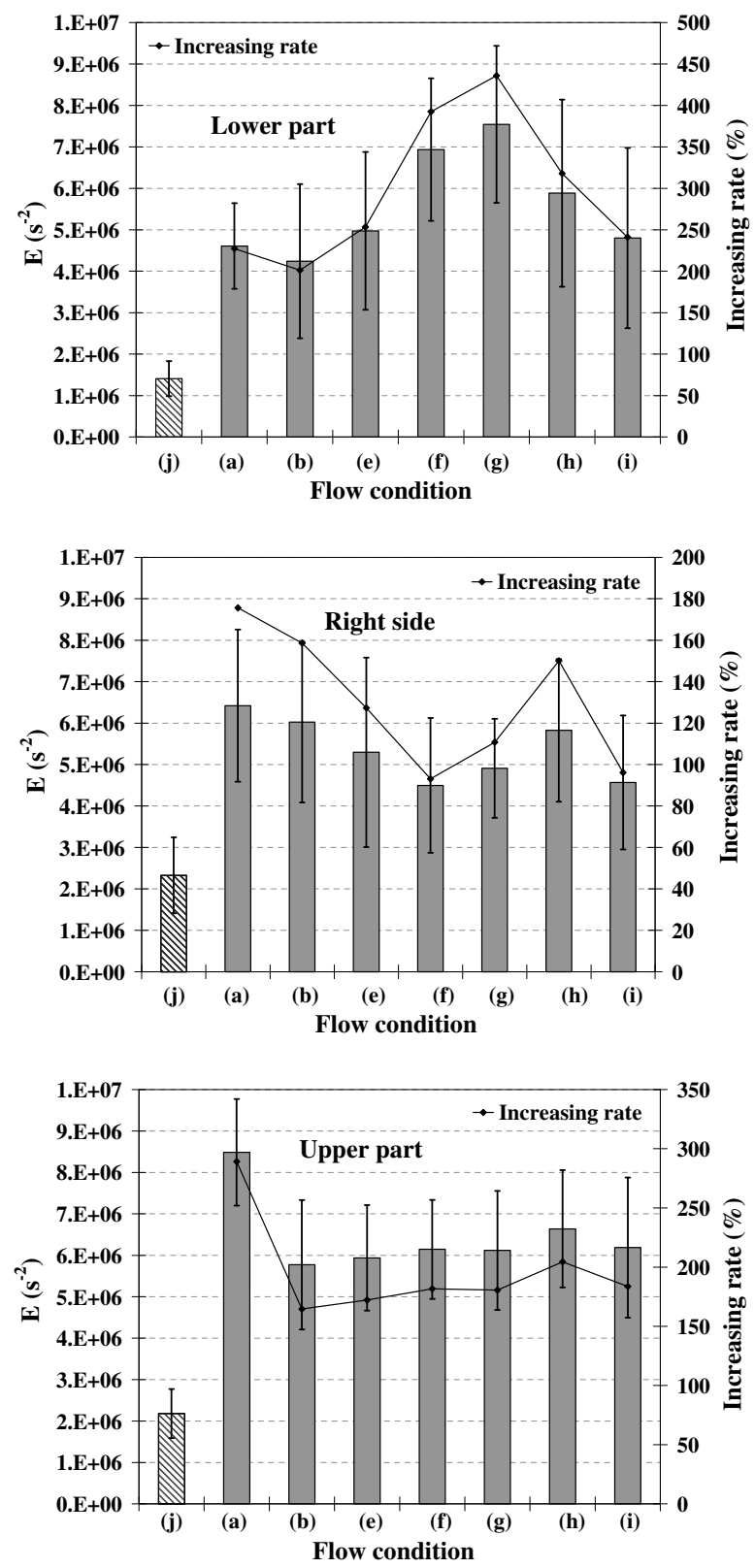

Fig. 8. Comparison of fluctuation energies of the velocity gradient between the tested flow conditions and increasing rates compared to the steady flow. (Increasing rate $=100 \times($ pulsating value - steady value $) /$ steady value $)$.

ning of the spectrum is not linear as observed for the steady condition, but rises until a frequency around $3 \mathrm{~Hz}$. However, the increase of the fluctuation energy is not only due to the peaks induced by the frequency of the pulsations and its harmonics. This result can be verified in condition (b) which presents the same mean velocity than the steady flow $(1.47 \mathrm{~m} / \mathrm{s})$. For this condition, pulsations induce the increase of the total energy contained in the spectrum, which is still higher than the one observed in steady flow, even after peaks removal (Fig. 9b). On the contrary, Mao and Hanratty (1986) found that no significant difference of power spectra is observed between the pulsed flow without peaks and the steady condition for the same mean velocity. This disagreement can be explained by the low amplitude of the pulsations studied by these authors in comparison with the present study.

For the two conditions, the kinetic energy dissipation occurs according to a regression slope value around $-5 / 3$, which shows that under pulsating flows, the turbulence remains almost homogeneous and isotropic. Separated effects of the frequency and of the amplitude of the pulsations can be observed respectively for conditions (f) and (g). These two conditions are characterized by the highest frequency $(2.86 \mathrm{~Hz})$ and the largest amplitude $(0.81 \mathrm{~m} / \mathrm{s})$. Condition (f) presents high increasing rates of the fluctuation energy varying between $100 \%$ and $400 \%$ respectively at the right side and the lower part of the tube. Power spectral densities for this condition (Fig. 10a) exhibit a high number of peaks, corresponding to the pulsations frequency and its harmonics. In addition, these peaks reveal high amplitude, especially at low frequencies (under $10 \mathrm{~Hz}$ ), which explain the high values of the fluctuation energy.

Condition ( $g$ ) also exhibits a significant increase in the total energy fluctuations in comparison with steady flow. This condition, characterized by an important amplitude of the pulsations, highlights the effects of harmonics of the frequency of the pulsations in the fluctuation energy, illustrated by the large peaks (Fig. 10b) in comparison with the previous condition. Power spectrum superposition between the steady flow and both pulsating conditions ( $f$ ) and ( $\mathrm{g}$ ) for the same microelectrode (No 7 at the upper part) shows that the energy difference is observed at low frequencies (Fig. 10a and b). Indeed, from a frequency nearly equal to $15 \mathrm{~Hz}$, spectral densities present the same regression phase shape of the turbulent energy. This result can be induced by the same mean velocity of the flow for these two conditions $(1.03 \mathrm{~m} / \mathrm{s})$. However, the observed difference at low frequency is due to pulsations parameters variability of conditions (f) and ( $\mathrm{g}$ ).

The two conditions (e) and (h) present analogous frequency and amplitude of pulsations, only the mean flow velocity is different. In addition to the increase of the fluctuation energy of the two conditions compared with steady flow, slightly higher values are obtained with condition (h) $(150 \%, 200 \%$ and $320 \%$ against $130 \%$, $175 \%$ and $250 \%$ respectively at the right side, the upper and the lower parts for conditions (h) and (e)).

This result can be explained by the closeness between the amplitude of the pulsations and the average flow velocity for this condition (respectively $0.73 \mathrm{~m} / \mathrm{s}$ and $0.78 \mathrm{~m} / \mathrm{s}$ ). For this condition, the flow may be more disturbed due to the fact that parameter $A$ is close to 1 corresponding to the recirculation at the center pipe. However, despite this slight difference in the fluctuation energy between conditions (e) and (h), the analogy of pulsation parameters induces a high similarity in the power spectral densities observed at the first six probes localised at the upper part of the pipe (Fig. 11a and b).

The pulsation condition (i), characterized by the setup of a recirculation zone at the center core of the pipe, exhibits a significant improvement in the fluctuation energy with increasing rates varying from $100 \%$ to $250 \%$ between the right side and the lower part of the pipe. These important increasing rates can be explained by the high amplitude of the pulsations, which correspond to $R e_{\mathrm{p}}$ equal to 16500 . The recirculation zone establishment, due to the important amplitude of the pulsations compared with the mean flow velocity, induces the modification of the PSD shape (Fig. 12a). Indeed, the kinetic energy dissipation occurs with a regression slope higher than $-5 / 3$ (regression slope equal to -2.54 ) as shown in Fig. $12 b$. This result can be interpreted by sizes redistribution of eddies structures, with a fast degradation of large eddies due to the boundary layer confinement by the center core recirculation zone. In addition, the transition to small eddies, less energetic, is faster than in steady flow case, which explains the energy dissipation observed in Fig. 12a. This rapid energy dissipation takes place at high frequencies where the kinetic energy is not very important, which slightly modifies the total fluctuation energy. Moreover, at low frequencies, PSD shows energy levels which increase in addition to that generated by frequency pulsations peaks and their associated harmonics. 

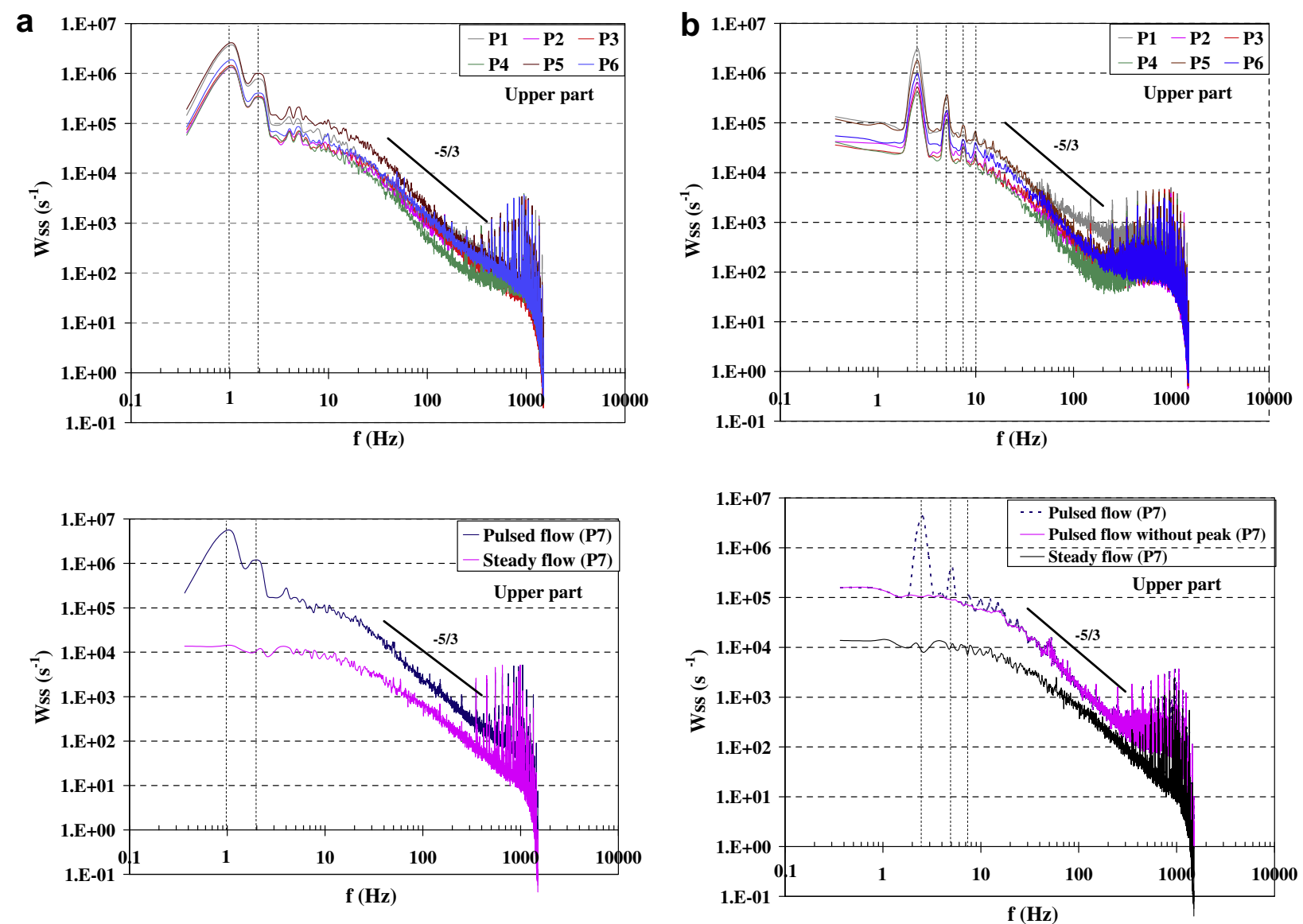

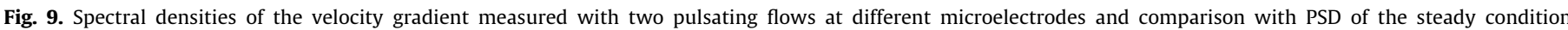
(microelectrode No 7 at the upper part). ("a" for condition (a) and "b" for condition (b)).
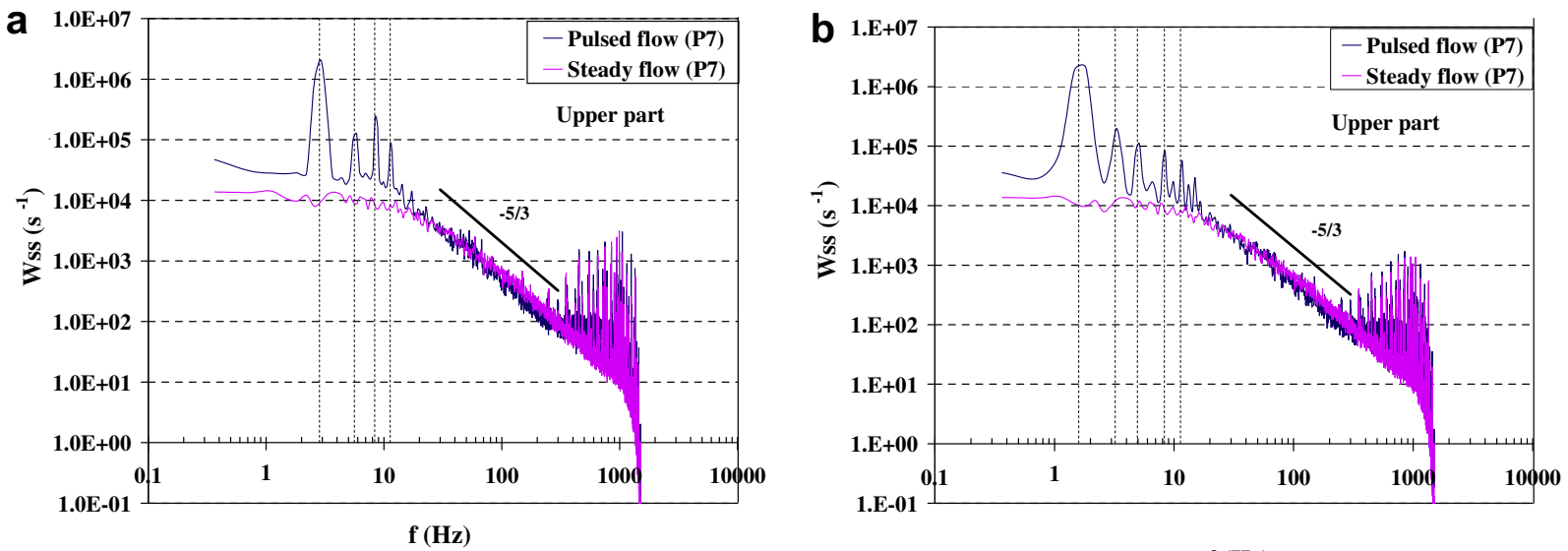

$\mathbf{f}(\mathbf{H z})$

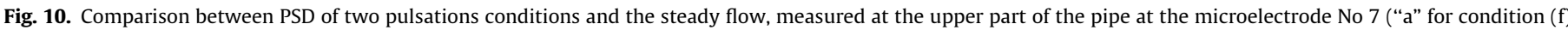
and "b" for condition ( $(\mathrm{g})$ ).

To summarize, the application of harmonic pulsations to a steady flow emphasizes an important increase in the fluctuation energy of the velocity gradient. Three parameters were investigated, the mean velocity flow, the amplitude and the frequency of the pulsations. These three parameters significantly contribute to the fluctuation energy increase. The amplitude and the frequency of the pulsations induce considerable changes in the PSD structure in the low frequencies range, which corresponds to the high kinetic energy. The condition with recirculating flow at the center core of the pipe reveals modifications in the dissipation energy slope induced by the redistribution of eddies sizes near the wall in comparison with Kolmogorov cascade.

\section{Conclusion}

Pulsating flow effects on wall shear stress components were analysed. Experiments were carried out using a new pulsations generation system at high amplitude of pulsations. 

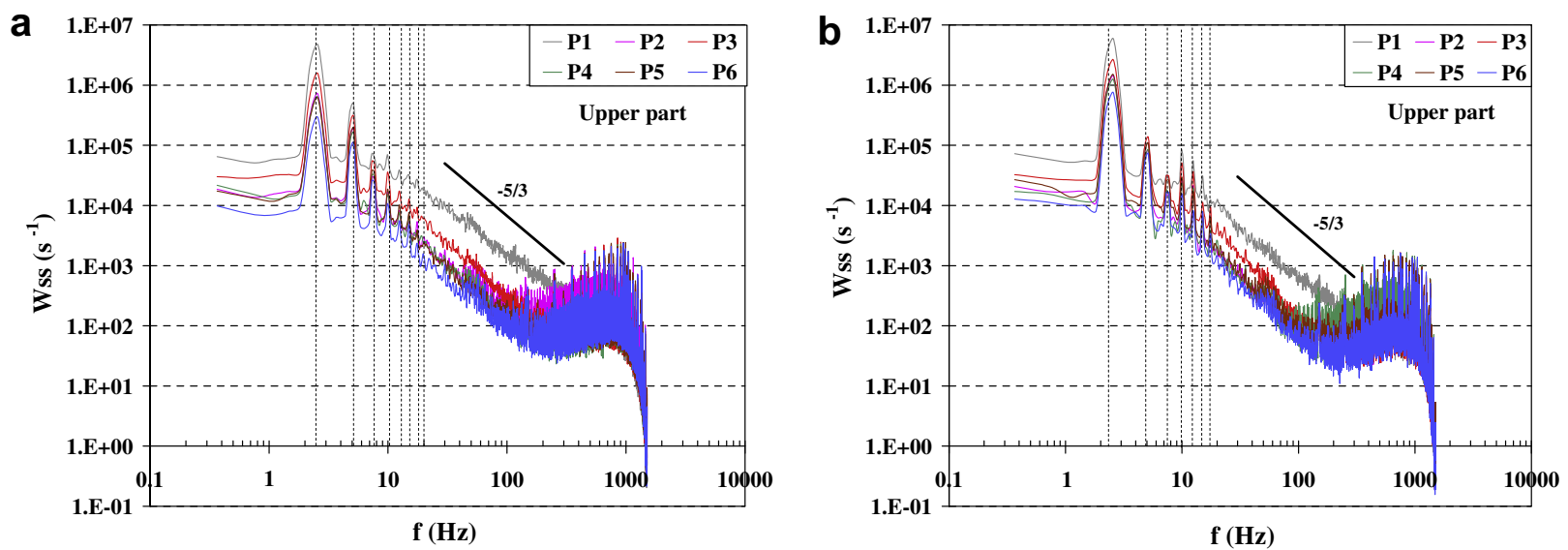

Fig. 11. Spectral densities of the velocity gradient measured with two pulsating flow at different microelectrodes ("a" for condition (e) and "b" for condition (h)).
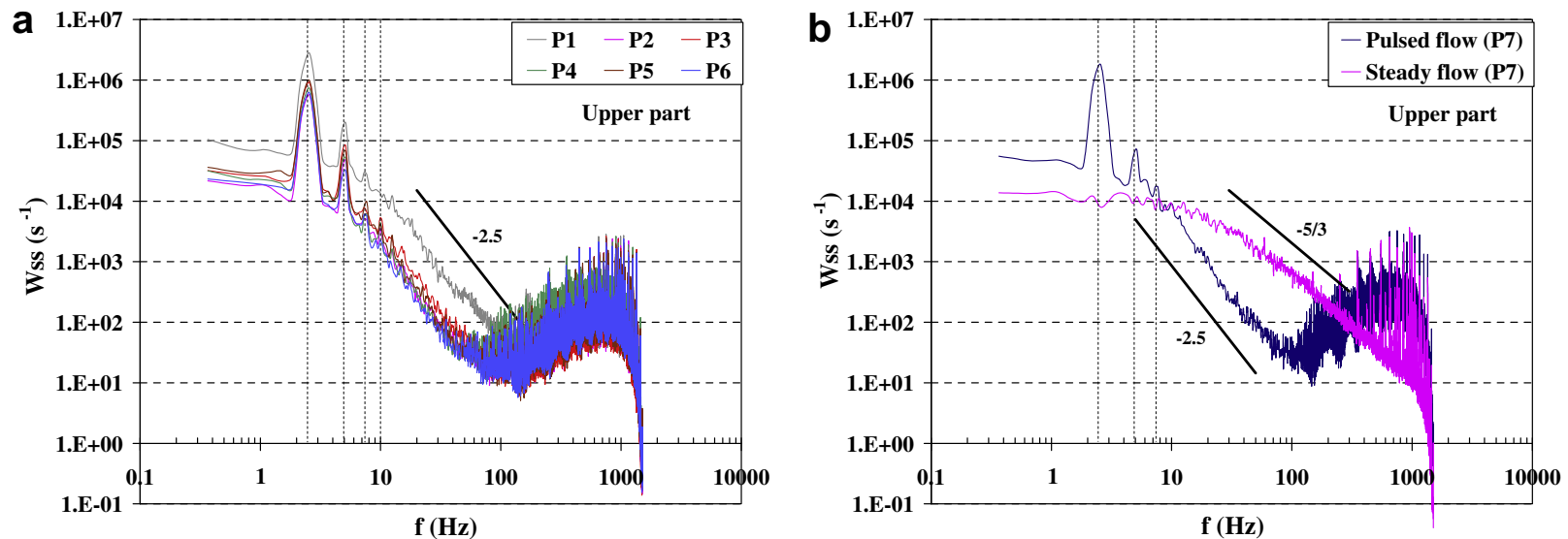

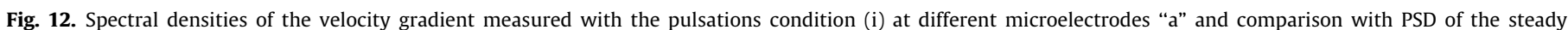
condition (microelectrode No 7 at the upper part) "b".

Wall shear stress values under different pulsations conditions (characterized by the variation of the mean flow velocity, the amplitude and the frequency), exhibit an important increase in the mean and in the fluctuation wall shear stress. The pulsation generator induces shear stress increase due to the important values of the amplitude of pulsations. In addition, for pulsating conditions with the same mean velocity, the frequency of the pulsations has been proven to be more effective on the shear stress than the amplitude parameter. On the other hand, the amplitude has a beneficial effect on the shear stress values when the mean velocity is not high enough.

Fluctuation energy measurements showed that the amplitude and the frequency of the pulsations induce considerable changes in the PSD structure in the range of low frequencies, which corresponds to the higher kinetic energy. Recirculation flow at the center core of the pipe induced by amplitude of the pulsations higher than the mean velocity reveals modifications in the wall boundary layer structure with more important dissipation energy slope in the PSD form.

For low mean velocity of the flow, in comparison with the steady condition, high increasing rates of both mean shear stress and fluctuation energy of the velocity gradient are obtained due to the important amplitude of the pulsations. This result demonstrates the interest of this flow which allows to obtain better performance in comparison with the reference state.
Finally, for both wall shear components, the observed improvements in the mean and the fluctuating value, in comparison with the steady flow, can be explained by the pulsating flow effects on the near-wall region, especially the boundary layer.

In future works, pulsating flow will be tested with loops containing diametrical changes and complex geometries in order to investigate pulsations effects on shear stress components of industrial flow configurations.

\section{Acknowledgements}

This work was supported by the French Ministry of Agriculture in the frame of a program involving different partners (CETIM, Laval Mayenne Technopole, LACTALIS R\&D, BOCCARD - Division Alimentaire, GOAVEC INGENIERIE, PIERRE GUERIN and SERVICE INDUSTRIEL TUYAUTERIE). Authors are very grateful to Laurent Bouvier, Pascal Debreyne, Jean Jacquemont, Jean-François Migdal, Jacky Six and Guillaume Roelens for their technical supports.

\section{References}

AI-Haddad, A.A., AI-Binally, N., 1989. Prediction of heat transfer coefficient in pulsating flow. International Journal of Heat and Fluid Flow 10, 131-133.

Bellanger, M., 2002. Traitement Numérique du Signal. Théorie et Pratique Edition Dunod, France.

Blel, W., Bénézech, T., Legentilhomme, P., Legrand, J., Le Gentil-Lelièvre, C., 2007. Effect of flow arrangement on the removal of Bacillus spores from stainless steel 
equipment surfaces during a cleaning in place procedure. Chemical Engineering Science 62, 3798-3808.

Brodkey, B.S., Hershey, H.C., 1988. Transport Phenomena, a Unified Approach. McGraw-Hill College, USA

Brunold, C.R., Hunns, J.C.B., Mackley, M.R., Thompson, J.W., 1989. Experimenta observations on flow patterns and energy losses for oscillatory flow in ducts containing sharp edges. Chemical Engineering Science 44, 1227-1244.

Cousteix, J., 1989. Turbulence et Couche Limite Collection La Chevêche. CépaduèsEditions. Toulouse, France.

Deslouis, C., Gil, O., Tribollet, B., 1990. Frequency response of electrochemical sensors in a cone and plate modulated flow. International Journal of Heat and Mass Transfer 33, 2525-2532.

Finnigan, S.M., Howell, J.A., 1989. The effect of pulsatile flow on ultrafiltration flux in a baffled tubular membrane systems. Chemical Engineering Research and Design 67, 278-282.

Gbadebo, S.A., Said, A.M., Habib, M.A., 1999. Average Nusselt number correlation in the thermal entrance region of steady and pulsating turbulent pipe flows. Heat and Mass Transfer 35, 377-381.

Gillham, C.R., Fryer, P.J., Hasting, A.P.M., Wilson, D.I., 2000. Enhanced cleaning of whey protein soils using pulsed flows. Journal of Food Engineering 46, 199-209.

Gomaa, H., Al Taweel, A.M., 2004. Dynamic analysis of mass transfer at vertically oscillating surfaces. Chemical Engineering Journal 102, 71-82.

Grassmann, P.P., Tuma, M., 1978. Applications of the electrolytic method-II. Mass transfer within a tube for steady, oscillating and pulsating flows. International Journal of Heat and Mass Transfer 22, 799-804.

Howes, T., Mackely, M.R., Roberts, E.P.L., 1991. The simulation of chaotic mixing and dispersion of periodic flows in baffled channels. Chemical Engineering Science 46, 1669-1677.

Jensen, B.B.B., Friis, A., Bénézech, T., Legentilhomme, P., Lelièvre, C., 2005. Local wall shear stress variations predicted by computational fluid dynamics for hygienic design. Transaction of the Institute of Chemical Engineers, Part C. Food and Bioproducts Processing 83, 1-8.

Labraga, L., Lagraa, B., Mazouz, A., Keirsbulck, L, 2002. Propagation of shear-layer structures in the near-wall region of a turbulent boundary layer. Experiments in Fluids 33, 670-676.

Lelièvre, C., Legentilhomme, P., Gaucher, C., Legrand, J., Faille, C., Bénézech, T., 2002. Cleaning in place: effect of local wall shear stress variation on bacterial removal from stainless steel equipment. Chemical Engineering Science 57, 1287-1297.
Lemlich, R., 1961. Vibration and pulsation boost heat transfer. Chemical Engineering $68,171-176$.

Mackley, M.R., Stonestreet, P., 1995. Heat transfer and associated energy dissipation for oscillatory flow in baffled tubes. Chemical Engineering Science 50, 2211 2224.

Mao, Z.X., Hanratty, T.J., 1985. The use of scalar transport probes to measure wall shear stress in a flow with imposed oscillations. Experiments in Fluids 2, 129135.

Mao, Z.X., Hanratty, T.J., 1986. Studies of the wall shear stress in a turbulent pulsating pipe flow. Journal of Fluid Mechanics 170, 545-564.

Mao, Z.S., 1995. Numerical analysis of higher order harmonics in the response of a mass transfer probe. International Journal of Heat and Mass Transfer 38, 26672675.

Martinelli, R.C., Boelter, L.M.K., Weinberg, E.B., Yakahi, S., 1943. Heat transfer to a fluid flowing periodically at low frequencies in a vertical tube. Transactions of the American Society of Mechanical Engineers 65, 789-798.

Paek, J.W., Kang, B.H., Hyun, J.M., 1999. Transient cool-down of a porous medium in pulsating flow. International Journal of Heat and Mass Transfer 42, 3523-3527.

Pérez-Herranz, V. Guiñón, J.L. García-Antón, J., 1999. Analysis of mass and momentum transfer in an annular electrodialysis cell in pulsed flow. Chemical Engineering Science 54, 1667-1675.

Quinquis, A., 2000. Le traitement de signal sous Matlab: pratique et applications. Edition Hermes, France.

Rehimi, F., Aloui, F., Ben Nasrallah, S., Doubliez, L., Legrand, J., 2006. Inverse method for electrodiffusional diagnostics of flows. International Journal of Heat and Mass Transfer 49, 1242-1254.

Reiss, L.P., Hanratty, T.J., 1963. An experimental study of the unsteady nature of the viscous sublayer. AIChE Journal 8, 154-160.

Sobolik, V., Wein, O., Cermak, J., 1987. Simultaneous measurement of film thickness and wall shear stress in wavy flow of non-Newtonian liquids. Collection of Czechoslovak Chemical Communications 52, 913-928.

Takeda, Y., 1995. Velocity profile measurement by ultrasonic Doppler method. Experimental Thermal and Fluid Science 10, 444-453.

Wang, X., Zhang, N., 2005. Numerical analysis of heat transfer in pulsating turbulent flow in a pipe. Journal of Heat and Mass Transfer 48, 3957-3970.

Wang, T., Wang, J., Ren, F., Jin, Y., 2003. Application of Doppler ultrasound velocimetry in multiphase flow. Chemical Engineering Journal 92, 111-122. 